\title{
Assessment of Clinical Learning Environment, Supervision (CLES) among Nursing Students, Hyderabad, Sindh, Pakistan
}

\author{
Suriya Khatoon ${ }^{1}$ (D), Syed Yousaf Sha' ${ }^{2}$, Ajmal Khan ${ }^{3}$, Zulfiqar Ali ${ }^{4}$, Syed Arif Ali' \\ ${ }^{1}$ Shaheed Mohtarma Benazir Bhutto Medical University, Larkana, Pakistan \\ ${ }^{2}$ Dow University of Health Sciences, Karachi, Pakistan \\ ${ }^{3}$ Indus College of Nursing \& Midwifery, Karachi, Pakistan \\ ${ }^{4}$ Dua Institute of Nursing, Qasimabad, Pakistan \\ Email: suriya.nisar@gmail.com, sayedyousafshah@gmail.com, ajmalkhan320@gmail.com, zulfikhoso562@gmail.com, \\ arif_ali79@hotmail.com
}

How to cite this paper: Khatoon, S., Sha, S.Y., Khan, A., Ali, Z. and Ali, S.A. (2019) Assessment of Clinical Learning Environment, Supervision (CLES) among Nursing Students, Hyderabad, Sindh, Pakistan. Open Journal of Nursing, 9, 408-417.

https://doi.org/10.4236/ojn.2019.94037

Received: February 24, 2019

Accepted: April 15, 2019

Published: April 18, 2019

Copyright $\odot 2019$ by author(s) and Scientific Research Publishing Inc. This work is licensed under the Creative Commons Attribution International License (CC BY 4.0).

http://creativecommons.org/licenses/by/4.0/

\begin{abstract}
Background: In nursing education for better teaching and essential professional skills, the clinical practice plays a substantial role. Practice at clinical settings permits students to convert theoretic knowledge into the knowledge of the skills mandatory for the care of the patient. Clinical learning environment (CLE) is an important part in education of nursing and has a sizable influence on the students' learning. Objective: The purpose of this study is to examine perception and satisfaction of nursing students with their CLEs in Hyderabad, Pakistan. Methods: This cross-sectional study was conducted at three nursing institutes of Hyderabad from December 2018 to January 2019 among 342 nursing students. Clinical Learning Environment, Supervision and Nurse Teacher (CLES $+\mathrm{T}$ ) assessment tool was used as the instrument to identify the students' perception about the learning environment in clinical setting. Results: The mean age of the participants was $25.6 \pm 4.93$ with majority of them male $(70.7 \%)$. Three domains, pedagogical atmosphere, supervisory relationship and nurse teacher role in clinical practice showed good reliability of more than $70 \%$. Highest domains vise mean score was obtained for nursing premises on the ward (3.315) whereas lowest for nurse teacher role in clinical practice (NT) (3.062). Analysis of variance revealed that three domains supervisory relationship, leadership style of the ward manager and premises of nursing showed significant mean score difference among supervisor title. Conclusion: It was found that students valued positive supervision, ward manager leadership style premises of nursing on the ward as positive CLE. Learning environment varies between gender, clinical settings and
\end{abstract}


supervision. Medicine ward appeared to deliver the finest learning situations for the nursing program.

\section{Keywords}

Clinical Placement, Nursing Education, Supervisor, Clinical Environment

\section{Introduction}

In nursing education for better teaching and essential professional skills, the clinical practice plays a substantial role [1]. Practice at clinical settings permits students to convert theoretic knowledge into the knowledge of the skills mandatory for the care of the patient [2]. Nursing education is that type of education where skill-based technicality is an important factor hence there is a noteworthy practical necessity for the learners. Hence, the clinical learning environment (CLE) is an important part in education of nursing and has a sizable influence on the students' learning [3]. The CLE could be explained as an interactive forces' network in clinical area that affects the learners' outcomes [4]. It comprises encounter of numerous people student nurses i.e., nursing staff, patients, nurse mentors, physicians [5]. Experience for clinical education helps the mastery of cognitive, psychomotor and affective behaviors required for competent entry-level practice. Improvement in CLE is possible when ward processes and structures are active; nursing staff are respected, stirred, and have upright relationships along well communication with learners; good care with quality is provided and students are acknowledged as learners as they can contribute to care [6]. Assistance and positive environment in which students are viewed as fresher colleagues [5] are also factors for enhancement. In addition to the clinical area academic environment, the relationship with supervisor, style of the leadership of manager at ward and care quality are vital for developing a decent learning environment [5] [7].

Furthermore, it is substantial that there should be a collaboration between health-care and educational institutions regarding the clinical learning environment [8]. Insufficient communication between above-mentioned institutions can lead to tension and less support, hence affect students to learn throughout their placement. Researches showed that a decent learning environment at clinical settings is helped through collaboration between nurse teacher and clinical staff [5] [9].

Some researches considered ward managers part with respect to sustaining and developing a decent learning environment although this character is important [10]. An observational study [11], which was conducted at three Swedish universities in 2011 among 185 nursing students, found that there was no significance difference of satisfaction of nursing students through the placement between clinical settings. Though, those placed in clinical departments of hospital 
strongly agreed that satisfactory learning circumstances were multi-dimensional and substantial learning circumstances occurred.

This purpose of this study is to examine perception and satisfaction of nursing students with their CLEs in Hyderabad, Pakistan. It is beneficial to understand expectation of the students for their clinical experience to provide a positive CLE and proper supervision. Findings from this study may play a part to increase supervisors' awareness of instructing and teaching to the students.

\section{Methodology}

This cross-sectional study was conducted at three nursing institutes, School of Nursing Liaqat University, Hospital, Jamshoro, Dua Institute of Nursing, Qasimaad, Hyderabad, School of Nursing, Sir Cowasjee Jehangir Institute of Psychiatry Hyderabad from December 2018 to January 2019. Nursing students of age greater than 16 years of either gender were selected through non-probability purposive sampling method from the three nursing schools. At first instance permission was obtained from the all principal of the schools then verbal and written consents were taken from individual students to participate in this study. Sample size was calculated through WHO online software OpenEpi v.3.0. By using percentage of nursing student agreement of satisfaction of clinical placement as 85.4\% [11], margin of error as $5 \%$ and confidence level as $99 \%$ the calculated sample size was 331, however we were able to take data from 342 nursing students. It has 34 questions on a five-point Likert scale, fully agree to fully disagree. All students completed the questionnaire as students filled questionnaire during the class after taking permission from the class/subject teacher. Hence response rate was $100 \%$ and all the questions were available for the statistical analysis. It has five domains, "Pedagogical atmosphere on the ward", "Leadership style of the ward manager", "Premises of nursing on the ward", "Supervisory relationship" and "Role of the nurse teacher in clinical practice" 9, 4, 4, 8 and 9 items respectively. Frequencies (percentages) and means (standard deviations) were obtained for the demographics characteristics and learning environment. Cronbach alpha was calculated for reliability analysis. Independent sample t-test was employed to look domain vise mean score between genders of nursing students. Analysis of variance was also used to identify significant mean score difference of clinical learning environment among supervisor title and clinical placement. P-value less than equals to alpha was considered as significant.

\section{Results}

Table 1 depicts demographic and clinical placement characteristics of the nursing students. The mean age of the participants was $25.6 \pm 4.93$ with majority of them male (70.7\%). The most prominent type of the program was Registered Nurse with $1^{\text {st }}$ year of education. Most of the students (68.6\%) were under supervision of nurse, with few under supervision of ward managers, nurse specialists and nurse teacher. Half of the study participants mentioned that their clinical 
Table 1. Demographic and clinical placement characteristics of nursing students.

\begin{tabular}{|c|c|c|}
\hline Characteristic & $\mathbf{n}$ & $\%$ \\
\hline Age (years) & $25.67 \pm 4.933$ & \\
\hline $18-22$ & 135 & 34.4 \\
\hline $23-27$ & 96 & 24.5 \\
\hline $28-32$ & 123 & 31.4 \\
\hline$>32$ & 38 & 9.7 \\
\hline \multicolumn{3}{|l|}{ Gender } \\
\hline Male & 277 & 70.7 \\
\hline Female & 115 & 29.3 \\
\hline \multicolumn{3}{|l|}{ Type of program } \\
\hline $\mathrm{RN}$ & 153 & 39.0 \\
\hline $\mathrm{BScN}$ Generic & 68 & 17.3 \\
\hline BScN Post RN & 86 & 21.9 \\
\hline Specialty & 85 & 21.7 \\
\hline \multicolumn{3}{|l|}{ Year of education } \\
\hline 1st Year & 216 & 55.1 \\
\hline 2nd Year & 146 & 37.2 \\
\hline 3rd Year & 30 & 7.7 \\
\hline Number of clinical courses completed & $7.50 \pm 3.017$ & \\
\hline$<5$ clinical courses & 102 & 26.0 \\
\hline 5 - 10 clinical courses & 260 & 66.3 \\
\hline$>10$ clinical courses & 30 & 7.7 \\
\hline \multicolumn{3}{|l|}{ Supervisor title } \\
\hline Nurse & 269 & 68.6 \\
\hline Nurse specialist & 41 & 10.5 \\
\hline Ward manager & 42 & 10.7 \\
\hline Nurse teacher & 40 & 10.2 \\
\hline \multicolumn{3}{|l|}{ Clinical placement } \\
\hline Medicine ward & 198 & 50.5 \\
\hline Surgery ward & 129 & 32.9 \\
\hline Plead ward & 65 & 16.6 \\
\hline
\end{tabular}

Duration of current/last clinical placement

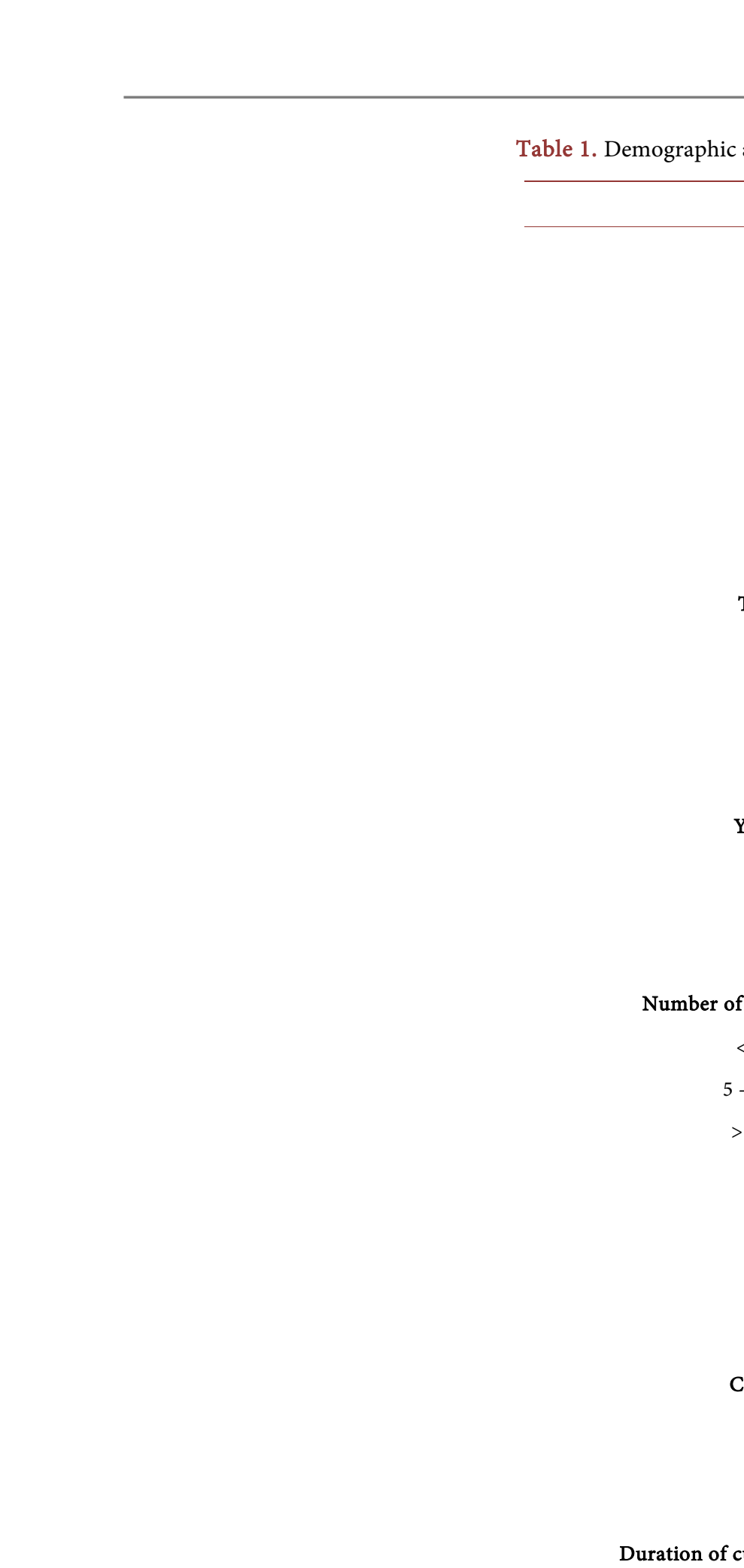

$\begin{array}{lcc}3 \text { weeks } & 71 & 18.1 \\ 4 \text { weeks } & 63 & 16.1 \\ >4 \text { weeks } & 102 & 26.0 \\ & 156 & 39.8\end{array}$

Frequency of supervision 


\begin{tabular}{lcc} 
Continued & & \\
\hline $\begin{array}{c}\text { More than one supervisor } \\
\quad \begin{array}{c}\text { placement } \\
\text { A personal supervisor, but the relationship did not work during the }\end{array}\end{array}$ & 28 & 25.3 \\
$\begin{array}{c}\text { The named supervisor changed during the placement } \\
\text { The supervisor varied according to shift or place of work }\end{array}$ & 4.1 \\
$\begin{array}{c}\text { Same supervisor had several students and was a group supervisor } \\
\text { A personal supervisor was named and relationship worked during } \\
\text { this placement }\end{array}$ & 161 & 1.0 \\
Satisfaction level & 32 & 4.1 \\
Very unsatisfied & & 8.2 \\
Unsatisfied & 24 & 6.1 \\
Neither unsatisfied nor satisfied & 44 & 11.2 \\
Satisfied & 74 & 18.9 \\
Very satisfied & 158 & 40.3 \\
& 92 & 23.5 \\
\hline
\end{tabular}

placement was medical ward followed by surgery and plead wards. There were $13.3 \%$ students who mentioned no supervision, one-fourth reported more than one supervision and according to $41.1 \%$ nursing students the similar supervisor had many students or was a supervisor of whole group. Nearly one-fourth of the nursing students was very satisfied with clinical environment and supervision, $40.3 \%$ satisfied and only $6.1 \%$ was very unsatisfied.

Table 2 shows domain vise mean scores of each item of (CLES $+\mathrm{T})$ and reliability analysis. Highest domains vise mean score was obtained for nursing premises on the ward (3.315) whereas lowest for nurse teacher role in clinical practice (NT) (3.062). Three domains, Pedagogical atmosphere, Supervisory relationship and nurse teacher role in clinical practice showed good reliability more than $70 \%$. Whereas reliabilities of other two domains Leadership style of the ward manager, Premises of nursing on the ward were 0.489 and 0.606 respectively.

Table 3 exhibits association of gender with clinical learning environment and supervision among nursing students. For both genders highest mean scores was obtained for Premises of nursing and lowest mean scores for Role of the nurse teacher. All domains showed significant mean score difference between male and female nursing students except Premises of nursing domain.

Table 4 shows association of supervisor title with clinical learning environment and supervision among nursing students. Analysis of variance revealed that three domains Supervisory relationship, Leadership style of the ward manager and Premises of nursing showed significant mean score difference among supervisor title. For Supervisory relationship, Leadership style of the ward manager the highest mean scores were found for Nurse teacher whereas lowest for Nurse specialist. However, for Premises of nursing highest mean score was reported for Ward manager and lowest for Nurse specialist. 
Table 2. The nursing students' assessment of the learning environment.

\section{Pedagogical atmosphere on the ward}

The staff was easy to approach

I felt comfortable going to the ward at the start of my shift

During staff meetings (e.g. before shifts) I felt comfortable taking part in the discussions

There was a positive atmosphere on the ward

The staff was generally interested in student supervision

The staff learned to know the students by their personal names

There were sufficient meaningful learning situations on the ward

The learning situations were multi-dimensional in terms of content

The ward can be regarded as a good learning environment

\section{Leadership style of the ward manager (WM)}

The WM regarded the staff on her/his ward as a key resource

The WM was a team member

Feedback from the WM could easily be considered a learning situation

The effort of individual employees was appreciated

Premises of nursing on the ward

The wards nursing philosophy was clearly defined

Patients received individual nursing care

Documentation of nursing (e.g. nursing plans, daily recording of nursing procedures) was clear

There were no problems in the information flow related to patients' care

Supervisory relationship

My supervisor showed a positive attitude towards supervision

I felt that I received individual supervision

I continuously received feedback from my supervisor

Overall I am satisfied with the supervision I received

The supervision was based on a relationship of equality and promoted my learning

There was a mutual interaction in the supervisory relationship

Mutual respect and approval prevailed in the supervisory relationship

The supervisory relationship was characterized by a sense of trust

Role of the nurse teacher in clinical practice (NT)

In my opinion, the NT was capable of integrating theoretical knowledge and everyday practice of nursing

The NT was capable of operationalizing the learning goals of this placement

The NT helped me to reduce the theory-practice gap

\begin{tabular}{|c|c|c|}
\hline Mean & SD & Alpha \\
\hline 3.0754 & 0.77596 & 0.774 \\
\hline 2.92 & 1.327 & \\
\hline 3.03 & 1.253 & \\
\hline 3.18 & 1.322 & \\
\hline 2.92 & 1.246 & \\
\hline 3.08 & 1.306 & \\
\hline 2.97 & 1.364 & \\
\hline 3.11 & 1.245 & \\
\hline 3.27 & 1.321 & \\
\hline 3.21 & 1.314 & \\
\hline 3.1263 & 0.69778 & 0.489 \\
\hline 2.99 & 1.618 & \\
\hline 3.19 & 1.187 & \\
\hline 3.30 & 1.266 & \\
\hline 3.02 & 0.687 & \\
\hline 3.3152 & 0.75938 & 0.606 \\
\hline 3.24 & 1.248 & \\
\hline 3.35 & 1.181 & \\
\hline 3.34 & 1.239 & \\
\hline 3.22 & 1.180 & \\
\hline 3.20 & 0.76 & 0.758 \\
\hline 3.05 & 1.280 & \\
\hline 3.28 & 1.139 & \\
\hline 3.30 & 1.280 & \\
\hline 3.34 & 1.287 & \\
\hline 3.15 & 1.320 & \\
\hline 3.21 & 1.219 & \\
\hline 3.16 & 1.257 & \\
\hline 3.14 & 1.259 & \\
\hline 3.0624 & 0.41264 & 0.721 \\
\hline 2.98 & 0.711 & \\
\hline 3.19 & 0.734 & \\
\hline 3.06 & 0.800 & \\
\hline
\end{tabular}




\section{Continued}

\begin{tabular}{|c|c|c|}
\hline The NT was like a member of the nursing team & 3.08 & 0.768 \\
\hline The NT was able to give his or her expertise to the clinical team & 3.02 & 0.760 \\
\hline The NT and the clinical team worked in supporting my learning & 3.04 & 0.784 \\
\hline $\begin{array}{l}\text { The common meetings between myself, mentor and NT were comfortable } \\
\text { experience }\end{array}$ & 3.06 & 0.727 \\
\hline In our common meetings I felt that we are colleagues & 3.08 & 0.842 \\
\hline Focus on the meetings was on my learning needs & 3.08 & 0.725 \\
\hline
\end{tabular}

Table 3. Association of gender and clinical learning environment and supervision among nursing students.

\begin{tabular}{|c|c|c|c|c|c|c|}
\hline \multirow{2}{*}{$\begin{array}{c}\text { Gender } \\
\text { CLES }\end{array}$} & \multicolumn{2}{|c|}{ Male } & \multicolumn{2}{|c|}{ Female } & \multicolumn{2}{|c|}{$\begin{array}{l}\text { Independent sample } \\
\text { t-test }\end{array}$} \\
\hline & Mean & SD & Mean & SD & Statistic & $P$-value \\
\hline Supervisory relationship & 3.1512 & 0.76287 & 3.3326 & 0.75834 & -2.148 & 0.032 \\
\hline Pedagogical atmosphere & 3.0205 & 0.78384 & 3.2077 & 0.74340 & -2.186 & 0.029 \\
\hline Role of the nurse teacher (NT) & 3.0074 & 0.36311 & 3.1988 & 0.49114 & -4.175 & $<0.001$ \\
\hline $\begin{array}{c}\text { Leadership style } \\
\text { of the ward manager (WM) }\end{array}$ & 3.0668 & 0.58286 & 3.2696 & 0.90451 & -2.640 & 0.009 \\
\hline Premises of nursing & 3.3079 & 0.79065 & 3.3329 & 0.68111 & -0.297 & 0.767 \\
\hline
\end{tabular}

CLES: Clinical learning environment and supervision.

Table 4. Association of supervisor title and clinical learning environment and supervision among nursing students.

\begin{tabular}{|c|c|c|c|c|c|c|c|c|c|c|}
\hline \multirow{2}{*}{$\begin{array}{c}\text { Supervisor title } \\
\text { CLES }\end{array}$} & \multicolumn{2}{|c|}{ Nurse } & \multicolumn{2}{|c|}{ Nurse specialist } & \multicolumn{2}{|c|}{ Ward manager } & \multicolumn{2}{|c|}{ Nurse teacher } & \multicolumn{2}{|c|}{ ANOVA } \\
\hline & Mean & SD & Mean & SD & Mean & SD & Mean & SD & Statistic & P-value \\
\hline Supervisory relationship & 3.1357 & 0.75577 & 3.1006 & 0.50406 & 3.3690 & 0.87997 & 3.6000 & 0.79673 & 5.362 & 0.001 \\
\hline Pedagogical atmosphere & 3.0785 & 0.74349 & 2.9621 & 0.47376 & 2.9577 & 0.94566 & 3.2944 & 0.99494 & 1.687 & 0.169 \\
\hline Role of the nurse teacher (NT) & 3.0600 & 0.41920 & 2.9912 & 0.27141 & 3.0684 & 0.49271 & 3.1425 & 0.39486 & 0.871 & 0.456 \\
\hline $\begin{array}{c}\text { Leadership style of the ward } \\
\text { manager (WM) }\end{array}$ & 3.1041 & 0.74303 & 2.8841 & 0.43336 & 3.2679 & 0.62565 & 3.3750 & 0.57735 & 4.102 & 0.007 \\
\hline Premises of nursing & 3.2406 & 0.75422 & 3.0174 & 0.44971 & 3.7415 & 0.71271 & 3.6750 & 0.81905 & 11.183 & $<0.001$ \\
\hline
\end{tabular}

CLES: Clinical learning environment and supervision; SD: Standard deviation; ANOVA: Analysis of variances.

Table 5 reveals association of clinical placement with clinical learning environment and supervision among nursing students. Analysis of variance confirmed that there was significant mean score difference for all domains among different clinical placements. From Table 5 it is cleared that for all domains highest mean scores were reported for Medicine ward and lowest means of Supervisory relationship, Pedagogical atmosphere and Premises of nursing were reported for Plead ward and other remaining two domains showed lowest mean score for Surgery ward. 
Table 5. Association of clinical placement and clinical learning environment and supervision among nursing students.

\begin{tabular}{|c|c|c|c|c|c|c|c|c|}
\hline \multirow{2}{*}{$\begin{array}{c}\text { Clinical placement } \\
\text { CLES }\end{array}$} & \multicolumn{2}{|c|}{ Medicine ward } & \multicolumn{2}{|c|}{ Surgery ward } & \multicolumn{2}{|c|}{ Plead ward } & \multirow{2}{*}{\multicolumn{2}{|c|}{$\begin{array}{c}\text { ANOVA } \\
\text { StatisticP-value }\end{array}$}} \\
\hline & Mean & SD & Mean & SD & Mean & SD & & \\
\hline Supervisory relationship & 3.3889 & 0.82424 & 3.0320 & 0.67428 & 2.9846 & 0.60091 & 12.398 & $<0.001$ \\
\hline Pedagogical atmosphere & 3.2155 & 0.88065 & 2.9345 & 0.65169 & 2.9282 & 0.56500 & 6.712 & 0.001 \\
\hline $\begin{array}{l}\text { Role of the nurse teacher } \\
\qquad(\mathrm{NT})\end{array}$ & 3.1386 & 0.48623 & 2.9691 & 0.29064 & 3.0194 & 0.33126 & 7.016 & 0.001 \\
\hline $\begin{array}{l}\text { Leadership style of the } \\
\text { ward manager (WM) }\end{array}$ & 3.2197 & 0.62343 & 2.9884 & 0.52836 & 3.1154 & 0.107445 & 54.376 & 0.013 \\
\hline Premises of nursing & 3.5000 & 0.79269 & 3.1484 & 0.70832 & 3.0835 & 0.60761 & 12.720 & $<0.001$ \\
\hline
\end{tabular}

CLES: Clinical learning environment and supervision; SD: Standard deviation; ANOVA: Analysis of variances.

\section{Discussion}

This study deals satisfaction and perception of nursing students with the clinical learning environment. Finding of the study exhibited that student nurses were satisfied with their clinical placement experiences. In our study leadership style varied significantly among clinical placements. Students in a medicine ward thought that the managers valued the efforts of the staff, viewed them as a main resource and was one of the team. Students in plead ward showed least mean score of supervisory relationship. A cross-sectional study [11] conducted at three different Swedish universities showed that highest mean score of leadership style was obtained for psychiatric department whereas lowest for community-based settings and similar results were also obtained for Norwegian study [12]. In our study pedagogical atmosphere was also differed among clinical settings and highest mean score was obtained for medicine ward whereas lowest for plead ward. However study of Bisholt et al. [11] did not show significant means score of pedagogical atmosphere for different clinical settings. In this study we found less scores for items regarding the co-operation between the Nurse Teacher and staff this is in line with the findings of studies [9] [11] [13] [14]. The low scores might be attributable to the reality that items' wording in CLES $+\mathrm{T}$ for example "The nurse teacher was like a member of the nursing team" do not resemble to the part of the nurse teacher in current-day education of nursing academia [9].

Students in nursing might think that there is substantial learning. Though, consideration requires to both to where various clinical placements are planned inside the program and to the clinical areas provide learning chances and permit them to attain the objectives [15]. The strong point of current study is being the first attempt to explore area of nursing undergraduate education with a standardized instrument in Hyderabad Sindh. Clinical training of nursing students shares same educational needs and systematic rules such as practical training of different other health care students (dentists, doctors and midwives, etc.) at undergraduate level. Nevertheless, there is a dearth of similar relative studies in 
health care education field, primarily for the reason that different instruments used.

\section{Conclusion}

It was found that students valued positive supervision, ward manager leadership style premises of nursing on the ward as positive CLE. Learning environment varies between gender, clinical settings and supervision. Medicine ward appeared to deliver the finest learning situations for the nursing program. It is important that the clinical setting fulfills the requirements regarding a good learning environment so that student considers that the learning is substantial and follows a progression.

\section{Limitations}

This research can be conducted to a miscellaneous group of students from various institutional settings with longer period. Due to cross-sectional study design the cause-effect relationships of the effectiveness of the CLEST sub-dimensions could not be obtained. This can be achieved through Intervention research studies on integrated clinical teaching models and strategies.

\section{Conflicts of Interest}

The authors declare no conflicts of interest regarding the publication of this paper.

\section{References}

[1] Henriksen, N., Normann, H.K. and Skaalvik, M.W. (2012) Development and Testing of the Norwegian Version of the Clinical Learning Environment, Supervision and Nurse Teacher (CLES+T) Evaluation Scale. International Journal of Nursing Education Scholarship, 9. https://doi.org/10.1515/1548-923X.2239

[2] Nepal, B., Taketomi, K., Ito, Y.M., Kohanawa, M., Kawabata, H., Tanaka, M., et al. (2016) Nepalese Undergraduate Nursing Students' Perceptions of the Clinical Learning Environment, Supervision and Nurse Teachers: A Questionnaire Survey. Nurse Education Today, 39, 181-188. https://doi.org/10.1016/j.nedt.2016.01.006

[3] Hooven, K. (2014) Evaluation of Instruments Developed to Measure the Clinical Learning Environment: An Integrative Review. Nurse Educator, 39, 316-320. https://doi.org/10.1097/NNE.0000000000000076

[4] Dunn, S.V. (1995) The Development of a Clinical Learning Environment Scale. Journal of Advanced Nursing, 22, 1166-1173. https://doi.org/10.1111/j.1365-2648.1995.tb03119.x

[5] Papp, I., Markkanen, M. and von Bonsdorff, M. (2003) Clinical Environment as a Learning Environment: Student Nurses' Perceptions Concerning Clinical Learning Experiences. Nurse Education Today, 23, 262-268. https://doi.org/10.1016/S0260-6917(02)00185-5

[6] ABA (2003) Guidelines on the Key Points That May Be Considered When Developing a Quality Clinical Learning Environment. 3634.

[7] Saarikoski, M. and Leino-Kilpi, H. (2002) The Clinical Learning Environment and 
Supervision by Staff Nurses: Developing the Instrument. International Journal of Nursing Studies, 39, 259-267. https://doi.org/10.1016/S0020-7489(01)00031-1

[8] Bisholt, B. (2009) The Professional Socialisation of Newly Graduated Nurses Experiences of an Introduction Programme. Dissertation, The Sahlgrenska Academy Institute of Health and Care Sciences.

[9] Johansson, U.B., Kaila, P., Ahlner-Elmqvist, M., Leksell, J., Isoaho, H. and Saarikoski, M. (2010) Clinical Learning Environment, Supervision and Nurse Teacher Evaluation Scale: Psychometric Evaluation of the Swedish Version. Journal of Advanced Nursing, 66, 2085-2093.

[10] Maben, J., Latter, S. and Clark, J.M. (2006) The Theory-Practice Gap: Impact of Professional-Bureaucratic Work Conflict on Newly-Qualified Nurses. Journal of Advanced Nursing, 55, 465-477. https://doi.org/10.1111/j.1365-2648.2006.03939.x

[11] Bisholt, B., Ohlsson, U., Engström, A.K., Johansson, A.S. and Gustafsson, M. (2014) Nursing Students' Assessment of the Learning Environment in Different Clinical Settings. Nurse Education in Practice, 14, 304-310.

https://doi.org/10.1016/j.nepr.2013.11.005

[12] Skaalvik, M.W., Normann, H.K. and Henriksen, N. (2011) Clinical Learning Environment and Supervision: Experiences of Norwegian Nursing Students-A Questionnaire Survey. Journal of Clinical Nursing, 20, 2294-2304.

https://doi.org/10.1111/j.1365-2702.2011.03727.x

[13] Saarikoski, M., Warne, T., Kaila, P. and Leino-Kilpi, H. (2009) The Role of the Nurse Teacher in Clinical Practice: An Empirical Study of Finnish Student Nurse Experiences. Nurse Education Today, 29, 595-600.

https://doi.org/10.1016/j.nedt.2009.01.005

[14] Antohe, I., Riklikiene, O., Tichelaar, E. and Saarikoski, M. (2016) Clinical Education and Training of Student Nurses in Four Moderately New European Union Countries: Assessment of Students' Satisfaction with the Learning Environment. Nurse Education in Practice, 17, 139-144. https://doi.org/10.1016/j.nepr.2015.12.005

[15] Murphy, F., Rosser, M., Bevan, R., Warner, G. and Jordan, S. (2012) Nursing Students' Experiences and Preferences Regarding Hospital and Community Placements. Nurse Education in Practice, 12, 1 